\title{
Antibiotic Sensitivity Profile of Salmonella typhi Associated with Acute Diarrhoea Among Children in Kano, Nigeria
}

\author{
Muhammad Ali ${ }^{1 *}$ and Muhammad S Abdallah² \\ ${ }^{1}$ Department of Microbiology, Federal University Gusau, Nigeria \\ ${ }^{2}$ Desert Research Monitoring and Control Centre, Yobe State University Damaturu, Nigeria
}

Submission: May 15, 2019; Published: June 17, 2019

*Corresponding author: Muhammad Ali, Department of Microbiology, Federal University, Nigeria

\begin{abstract}
Acute diarrhoea remains as one of the most prevalent diseases affecting young children in developing countries. The objective of the study is to isolate, characterized and determine the antibiotic sensitivity profile of Salmonella typhi associated with acute diarrhoea among children in Kano, Nigeria. Thirty-seven (37) Faecal samples from children (ranges from 1 - 5 years) diagnosed with acute diarrhoea admitted to paediatric ward of Murtala Muhammad Specialist Hospital Kano were collected. The samples were streaked onto the surface of plate containing Nutrient agar using standard method for bacterial isolation. The Salmonella typhi was identified based on Gram staining, cultural characteristics and biochemical test. The bacteria isolate was subjected to antibiotic susceptibility testing using the agar disc diffusion method. The result showed 22 out of 37 samples were positive for Salmonella typhi which accounted for 59.6\%. Higher incidence of Salmonella was found among subjects of age between $2-3$ years. The sensitivity pattern of the isolate showed that it is sensitive to ampicillin, Augmentin, amoxicillin, levofloxacin and ciprofloxacin. Amoxicillin was found to be the most effect antibiotic with average zone of inhibition of $23.3 \mathrm{~mm}$. On the other hand, the isolate was resistant to streptomycin, pefloxacin, chloramphenicol, gentamicin and erythromycin. Findings of this study justify Salmonella as one of the bacteria causing acute diarrhoea in children.
\end{abstract}

Keywords: Antibiotics; Acute diarrhoea; Resistance; Salmonella Typhi; Sensitivity

\section{Introduction}

Diarrhoea remains among the most common cause of morbidity and mortality in children particularly in developing countries. In 2003alone, about6.3 million children died worldwide before reaching their fifth birthday with diarrhoea killing more than 500,000 of them [1]. Diarrhoea accounts for an estimated $3.6 \%$ of the global burden of disease, as expressed in disabilityadjusted life years [2]. Although mortality from diarrhoea has declined considerably over past 25 years worldwide, morbidity from diarrhoea in sub-Saharan Africa has not, as risk factors related to inadequate water, sanitation and hygiene, insufficient promotion of breast-feeding and malnutrition remain high [3]. The rapid growth of African cities and associated overcrowding has been linked to outbreaks of diarrhoea, with children under the age of five among the most affected [4]. In developing countries like Nigeria, most of Diarrhoeal infection is caused by virus, bacteria and other parasites. The major symptoms of diarrhoea in children including having 3 or more stools per day, watery bowel movements exceeding child's normal stool, with or without vomiting [5].
Acute diarrhoea might strike individuals at any age, but it is mostly an infant's disease, affecting especially those younger than one year [6]. The period of weaning is a major factor to favor the occurrence of diarrhoea, while many other risk factors should also be considered, such as low socioeconomic level, poor hygiene habits, unsavory dwelling, elevated environmental exposure to enteropathogenesis and poor nutritional status [7]. Salmonella, a member of the family Enterobacteriaceae, is a facultative anaerobic gram negative, non-spore forming rods that are indistinguishable from the Escherichia coli under the microscope or ordinary nutrient media [8]. They are widely distributed in the nature with humans and animals being their primary reservoirs. Salmonella food poisonings results from ingestion of food containing appropriate strains of this genus in significant numbers. Some significant changes have occurred in the taxonomy of Salmonella [9]. For epidemiological purposes, the Salmonella can be placed into three groups; the first are those that infect humans only. This includes, S. typhi, S. paratyphi $A, S$. Paratyphi $C$. this group includes the agents of typhoid and paratyphoid fevers, which are the most severe of disease caused by Salmonella. 
The epidemiology of Salmonella is complex, which often makes its control difficult and animals the epidemiology of the Salmonella is complex, which often make animals control of the disease is difficult and animals are the reservoir of the food borne illness of Salmonella $[10,11]$. Most cases of Salmonella occur as a result of ingesting contaminated food or water. Salmonella can also be acquired by contact with domestic animals and their products such as milk and meat, farm animals or animals in petting zoo, and exotic pets like turtles, hedgehogs, and iguanas [12]. Salmonella can also be transmitted from person to person via the oral-faecal route. The objective of the study is to isolate, characterized and determine the antibiotic sensitivity profile of Salmonella typhi associated with acute diarrhoea among children in Kano, Nigeria.

\section{Materials and Methods}

\section{Ethical Approval}

Ethical clearance (MOH/off/797/T. I/49) for the study was obtained from Kano State Ministry of Health through Health Service Management Board Kano with the consent of Murtala Muhammad Specialist Hospital Kano ethical committee.

\section{Study Area}

The study was conducted at paediatric ward of Murtala Muhammad Specialist Hospital Kano. Kano State is one of the states located in Northern Nigeria. It is geographically coordinated at $11030 \mathrm{~N}$ and $8030 \mathrm{E}$ latitude and longitude respectively. It shares borders with Kaduna state to the southwest, Bauchi state to the South-East, Jigawa state to the East, Katsina state to the West and Niger republic to the North. It has a total area of $20,131 \mathrm{~km} 2(7,777 \mathrm{sqm})$ and population of $11,058,300$ [13].

\section{Collection of Fecal Samples}

Table 1: Number and age distribution of the participants.

\begin{tabular}{|c|c|c|}
\hline Age (year) & Frequency $\mathbf{( n )}$ & Percentage (\%) \\
\hline Less than 1 & 7 & 18.9 \\
\hline $1-2$ & 11 & 29.7 \\
\hline $2-3$ & 9 & 24.4 \\
\hline $3-4$ & 6 & 16.2 \\
\hline $4-5$ & 4 & 10.8 \\
\hline Total & 37 & 100 \\
\hline
\end{tabular}

Thirty-seven (37) Fecal samples from children (ranges from 1 - 5 years) diagnosed with acute diarrhoea admitted to paediatric ward of Murtala Muhammad Specialist Hospital Kano were collected in clean, dry and leak proof sterile bottle from period of January to April 2017. The specimens were immediately transported to Laboratory of Science Laboratory Technology in School of Technology, Kano State Polytechnics for bacterial isolation and identification (Table 1).

\section{Isolation of Salmonella typhi}

Isolation of Salmonella typhi was conducted according to the method describe by Prescott et al. [14]. During the process, a sterile wire loop was deep into the fecal sample of the patients and streaked onto the surface of Nutrient agar (Life save Biotech, USA). The procedure was repeated for sample and the plates were incubated $370 \mathrm{C}$ for 24 hours. The presumptive colony of Salmonella typhi from each plate was further sub-cultured to obtained pure culture. The pure isolates of Salmonella typhi were preserved in peptone water for further use.

\section{Identification of Salmonella Typhi}

The preserved isolates were confirmed as S. typhi using conventional microbiological methods which include Gram staining, lactose fermentation and motility test as well as biochemical (Indole, methyl orange, voges proskauer, nitrate reduction and citrate utilization) tests according to the methods described by Chess brough [15] \& Holt et al. [16].

\section{Gram Staining}

Gram staining was done according to method described by Cheesbrough [15]. A thin smear was made by emulsifying an overnight culture of the isolate in normal saline on a well labelled clean glass slide. The smear was air dried and fixed by heat. This is followed by flooding the slide with crystal violet as primary stain for 30 seconds and then rinsed the slide with distilled water. The smear was flooded with Lugol's iodine as a mordant to fix the primary stain and then rinsed with distilled water after 60 seconds. The slide was decolorized using acetone and rinsed immediately. Counter stain with safranin followed and left for 30 before being rinsed off. The stain smear was air dried and observed under microscope.

\section{Biochemical test}

\section{Indole Test}

The tested organism was inoculated into peptone water and incubated at $370 \mathrm{C}$ for overnight, the kovaćs reagent was added. If there is pink ring the result was indicated as positive. If there is no pink ring in the surface the result was indicated as negative.

\section{Citrate Utilization Test}

In this test organism has ability to use citrate as only source of carbon. By straight loop apart of tested colonies was emulsified in kosser's citrate media and incubated at $370 \mathrm{C}$ for 24 hours. A blue colour with growth indicated as positive, no change in color indicated the negative result.

\section{Methyl Red and Voges Proskauer Test}

A pure culture of the test organism was inoculated in the MR/VP broth and incubated at $350 \mathrm{C}$ for 24 hours. Five Drops of $\mathrm{MR}$ reagent was added to the broth. A pure culture of the test organism was inoculated into MR/VP broth and incubated for 24 hours at $370 \mathrm{C}$. An aliquot of $1 \mathrm{ml}$ of the broth was added into a sterile test tube and add $0.6 \mathrm{ml}$ of VP reagent was added and shaken gently, then allowed it to expose into the atmosphere for 15 minutes. 


\section{Nitrate Reduction Test}

Nitrate broth was inoculated with an isolate of the test organism using sterile inoculating loop and incubated at $370 \mathrm{C}$ for 24 hours. A dropper full of sulfanilic acid and that of $\alpha$ naphthylamine were added to the broth.

\section{Motility Test}

The isolate was inoculated into motility medium by a fine stab with a sterile needle to a depth of $2 \mathrm{~cm}$ length of the bottom of the tube. It was then incubated at 370C for 24 hours. Line of inoculation was defined, and the medium was cleared for nonmotile organism while the line of inoculation was not defined for motile organism and the rest of the medium was somewhat cloudy for the motile organisms [15].

\section{Sensitivity Testing}

The S. typhi isolates were subjected to antibiotic susceptibility testing using the agar disc diffusion method as described by Bauer et al. [17]. Mueller Hinton agar (MHA) plates were inoculated with overnight culture of each isolate by streak plating. The standard antibiotic sensitivity discs were then aseptically placed at equidistance on the plates and allowed to stand for 1 hour. The plates were then incubated at $37^{\circ} \mathrm{C}$ for 24 hours. Sensitivity pattern of the isolates to Sparfloxacin $(30 \mu \mathrm{g})$, Streptomycin $(30 \mu \mathrm{g})$, Augmentin $(10 \mu \mathrm{g})$, Perfloxacin $(30 \mu \mathrm{g})$, Amoxacillin (30 $\mu \mathrm{g})$, Chloramphenicol $(30 \mu \mathrm{g})$, Gentamicin (10 $\mu \mathrm{g})$, Tavavid $(30 \mu \mathrm{g})$, Ciprofloxacin $(10 \mu \mathrm{g})$ and Septrin $(30 \mu \mathrm{g})$, produced by Abtek pharmaceutical limited, were determined. Isolates were divided into two groups based on the zone of inhibition produced by the antibiotic disc; susceptible and resistant according to the European committee on antimicrobial susceptibility testing (EUCAST) breakpoint for interpretation of MICs and zone diameters [18]. The experiment was conducted in triplicate and the average zone of inhibition was recorded.

Results

\section{Identification of Salmonella typhi}

The result for identification of Salmonella typhi is presented in (Table 1) below. The isolate was identified based on Gram staining, cultural characteristics and biochemical test. The result showed that the isolate is Gram negative bacteria, positive for MR and motility test but negative for indole, VP and citrate utilization test. The isolate cannot ferment lactose and produce transparent colourless colony in both MacConkey and Salmonella-Shigella agar

\section{Prevalence of Salmonella typhi}

The Prevalence of Salmonella in the fecal sample of child patients with acute diarrhoea is presented in (Table 2). The result showed 22 out of 37 samples were positive for Salmonella typhi which accounted for 59.6\%. Higher incidence of Salmonella was found among subjects of age between $2-3$ years (Table 3 ).
Table 2: Characterization of Salmonella typhi.

\begin{tabular}{|c|c|c|}
\hline S/N & Test & Inference \\
\hline 1 & Gram staining & - \\
\hline 2 & Indole & + \\
\hline 3 & Methyl-red & - \\
\hline 4 & Voges Proskauer & + \\
\hline 5 & Citrate utilization & + \\
\hline 6 & Nitrate reduction & - \\
\hline 7 & Motility & Transparent colorless \\
\hline 8 & Lactose fermentation & colony \\
\hline 9 & Salmonella-Shigella agar growth & . \\
\hline
\end{tabular}

Table 3: Prevalence of Salmonella in the faecal sample of child patients with acute diarrhoea.

\begin{tabular}{|c|c|c|c|}
\hline Age (year) & Frequency (n) & Salmonella + (n) & Prevalence (\%) \\
\hline Less than 1 & 7 & 3 & 8.2 \\
\hline $1-2$ & 11 & 5 & 13.5 \\
\hline $2-3$ & 9 & 7 & 18.9 \\
\hline $3-4$ & 6 & 5 & 13.5 \\
\hline $4-5$ & 4 & 2 & 5.5 \\
\hline Total & 37 & 22 & 59.6 \\
\hline
\end{tabular}

\section{Antibiotic Sensitivity Testing}

Table 4: Antibiotic Sensitivity testing of the isolates against some antibiotics.

\begin{tabular}{|c|c|c|c|c|}
\hline S/N & Antibiotics & $\begin{array}{c}\text { Conc. } \\
(\boldsymbol{\mu g})\end{array}$ & $\begin{array}{c}\text { Zone of } \\
\text { inhibition (mm) }\end{array}$ & Inference \\
\hline 1 & Ampicillin & 30 & $21.3 \pm 1.1$ & $\mathrm{~S}$ \\
\hline 2 & Streptomycin & 30 & $10.0 \pm 0.0$ & $\mathrm{R}$ \\
\hline 3 & Augmentin & 10 & $19.6 \pm 0.8$ & $\mathrm{~S}$ \\
\hline 4 & Perfloxacin & 30 & $12.3 \pm 0.1$ & $\mathrm{R}$ \\
\hline 5 & Amoxicillin & 30 & $23.3 \pm 0.9$ & $\mathrm{~S}$ \\
\hline 6 & Chloramphenicol & 30 & $11.0 \pm 0.1$ & $\mathrm{R}$ \\
\hline 7 & Gentamicin & 30 & $10.0 \pm 0.0$ & $\mathrm{R}$ \\
\hline 8 & Levi floxacin & 10 & $21.6 \pm 0.3$ & $\mathrm{~S}$ \\
\hline 9 & Ciprofloxacin & 30 & $22.3 \pm 1.2$ & $\mathrm{~S}$ \\
\hline 10 & Erythromycin & 10 & $13.6 \pm 0.7$ & $\mathrm{R}$ \\
\hline
\end{tabular}

Key: S: Sensitive, R: Resistance

The zone of inhibition of antibiotic sensitivity disc against the bacterial isolates is presented below (Table 4). Some of the antibiotics were active against the isolates while resistance to others. The isolate was sensitive to ampicillin, augmentin, amoxicillin, levifloxacin and ciprofloxacin. Amoxicillin was found to be the most effect antibiotic with average zone of inhibition of $23.3 \mathrm{~mm}$. On the other hand, the isolate was resistant to streptomycin, perfloxacin, chloramphenicol, gentamicin and erythromycin. 


\section{Juniper Online Journal of Public Health}

\section{Discussion}

Acute diarrhoea might strike at any age, but it is mostly a children disease affecting those younger than 5 years. The period of weaning is a major factor to favour the occurrence of diarrhoea, while many other risk factors such as low socioeconomic level, poor hygiene habits, unsavory dwelling, elevated environmental exposure to enteropathogenesis and poor nutritional status may be considered [7]. In (Table 2), the isolate was tested for gram staining and biochemical test. The isolate produces colourless and transparent colony on MacConkey and Salmonella-Shigella agar medium; hence cannot ferment lactose.

In the present study, S. typhi was found as one of the bacteria associated with acute diarrhoea in children. Out of 37 samples examined, 22 were positive for Salmonella typhi which accounted for $59.6 \%$. Higher incidence of Salmonella was found among subjects of age between 2-3 years. Several studies were conducted to characterize bacteria associated with gastrointestinal infection and found Salmonella as one of the bacteria associated with diarrhoea. One reason for pathogenicity in Salmonella is encoding system 1 type III secretion (T3SS-1) which is a virulence factor enabling the pathogen to invade the intestinal epithelium [19]. The finding of this study was in conformity with that of Nas et al. [20] on identification of some enteric bacterial isolates from diarrheic stool sample of adult male patients attending Murtala Muhammad Specialist Hospital Kano, Nigeria who found the presence of Escherichia coli, Salmonella spp, Klebsiella spp, Pseudomonas spp, Citrobacter spp and Shigella spp with the following prevalence $22 \%, 19 \%$, $14 \%, 12 \%, 14 \%, 19 \%$ respectively. Similar study was conducted by Obi et al. [21] on enteric bacterial pathogen in stools of residents of urban and rural regions of Nigeria, the results shows the most frequently encountered pathogens in rural area are E. coli, followed by Salmonella, Shigella, Enterobacter and Campylobacter. Similarly, the result of this study corresponds to the one conducted by Kim et al. [22] on bacteria isolated from diarrhoea patients in Korea which reveals that Escherichia coli as one of the most prevalent bacteria, then followed by Clostridium and Salmonella. A study conducted by Lopez et al. [23] on Entero-pathogenic agents isolated in persistent diarrhoea, the result shows that Salmonella, Escherichia coli and Shigella as the major enteric bacteria responsible for gastric disorder. This finding supported the present study.

On the sensitivity pattern of the isolates against the antibiotics used, some of the antibiotics were active against the isolates while resistance to others. The isolate was sensitive to ampicillin, augmentin, amoxicillin, levifloxacin and ciprofloxacin. Amoxicillin was found to be the most effect antibiotic with average zone of inhibition of $23.3 \mathrm{~mm}$. On the other hand, the isolate was resistant to streptomycin, perfloxacin, chloramphenicol, gentamicin and erythromycin. This finding showed Salmonella is sensitive to $\beta$ - lactam drugs (Amoxicillin and ampicillin) and fluroquinolones such as ciprofloxacin and levifloxacin. The $\beta$ - lactam drugs inhibit cell wall synthesis of the isolate while fluroquinolones attack DNA replication pathway. The result of this study supported the finding of Dessalegn et al. [24]. They found Salmonella isolates susceptible to ciprofloxacin. In Salmonella, there are multi genotypes resistance associated with plasmid that occur in gyr $\mathrm{A}$ and this resistance can be reversible by using fluroquinolones [25].

\section{Conclusion}

Acute diarrhoea remains as one of the most prevalent diseases affecting young children in developing countries. The findings of the study revealed that Salmonella is one of the bacteria associated with acute diarrhoea in children. It is highly prevalent among children diagnosed with acute diarrhoea. Sensitivity test of Salmonella against some antibiotics showed sensitivity to ampicillin, augmentin, amoxicillin, levifloxacin and ciprofloxacin and resistivity to streptomycin, perfloxacin, chloramphenicol, gentamicin and erythromycin. Proper environmental cleanliness, good personal hygiene and use balance diet is recommended for children. It also recommended that, antibiotics such as ciprofloxacin, amoxicillin and levifloxacin should be used in treatment of acute diarrhoea.

\section{References}

1. Liu L, Oza S, Hogan D, Perin J, Rudan I et al. (2015) Global, regional, and national causes of child mortality in $2000-13$, with projections to inform post 2015 priorities: an updated systematic analysis. Lancet 385(9966): 430-440.

2. Murray CI, Vos T, Lozano R, Naghavi M, Flaxman AD, et al. (2012) Disability-adjusted life years (DALYs) for 291 diseases and injuries in 21 regions, 1990-2010: a systematic analysis for the Global Burden of Disease study 2010. Lancet. 380(9859): 2197-2223.

3. Okeke IN (2009) Diarrhoeagenic Escherichia coli in sub-Saharan Africa: status, uncertainties and necessities. J Infect Dev Ctries 3(11): 817-842.

4. Sire JM, Garin B, Chartier L, Fall NK, Tall A, et al. (2013) Community-acquired infectious diarrhoea in children under 5 years of age in Dakar, Senegal. Paediatr Int Child Health 33(3): 139-144.

5. Churgay CA, Aftab Z (2012) Gastroenteritis in children: Part II. Prevention and management. Afr Med Fam Physician 85(11): 1066-1070

6. Haque R, Mondal D, Kirkpatrick BD, Akther S, Farr BM, et al. (2003) Epidemiologic and clinical characteristics of acute diarrhoea with emphasis on Entamoeba histolytica infections in preschool children in an urban slum of Dhaka, Bangladesh. Am J Trop Med Hyg 69(4): 398-405.

7. Moraes LR, Cancio JA, Cairncross S, Huttly S (2003) Impact of drainage and sewerage on diarrhoea in poor urban areas in Salvador, Brazil. Trans R Soc Trop Med Hyg 97(2): 153-158.

8. Lima AA, Fang G, Schorling JB, de Albuquerque L, McAuliffe JF, et al (1992) Persistent diarrhoea in Northeast Brazil: etiologies and interactions with malnutrition. Acta Paediatr Suppl 381: 39-44.

9. Le Minor and Popoff MP (1987) Designation of salmonella enteric species, nom, rev., as the type and only species of the genus salmonella. Int J Syst Evol Micr 37: 465-468.

10. Acha PN and Szyfres B (2001) Salmonellosis: in: zoonoses and communicable disease common to man and animal. $3^{\text {rd }}$ (edn) Pan American Health Organization, USA. 
11. Quinn PJ, Markey BK, Carter ME, Demnelly WJ and Leonard FC (2001) Veterinary microbiology and microbial disease. $8^{\text {th }}(\mathrm{edn})$ Blackwell publishing, oxford, UK.

12. Popoff MY, Bockemühl J and Brenner FW (2000) Supplement 1999 (no.43) to the Kauffmann-White scheme. Res Microbiol 151(10): 893896.

13. National Population Commission (2006) National population census result, Abuja Nigeria

14. Presscot LM, Harley JP and Klein DA (2005) Microbiology $6^{\text {th }}$ (Edn) McGraw Hill International edition NewYork.

15. Chessbrough M (2006) District laboratory practice in tropical countries, second edition, part two, Cambridge university press. Examination of pus, ulcer material and skin specimens pp: 80-85

16. Holt JG, Krieg NR, Senath PA, Staley JT , Williams ST (1994) Bergey's Manual of Determinative Bacteriology $9^{\text {th }}(\mathrm{Edn})$. Baltimore Md Williams and Wilkins.

17. Bauer AW, Kirby WM, Sherris JC, Turck M (1996) Antibiotic susceptibility testing by a standardized single disk method. Am J Clin Pathol 45(4): 493-496

18. EUCAST (2015) European committee on antimicrobial susceptibility testing (EUCAST) breakpoint for interpretation of MICs and zone diameters.

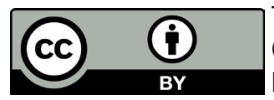

This work is licensed under Creative Commons Attribution 4.0 License

DOI: 10.19080/JOJPH.2019.04.555647
19. Yurist DS, Arrieta MC, Vogt SL, Finlay BB (2014) Gastrointestinal microbiota-mediated control of enteric pathogens. Annu Rev Genet 48: 361-382.

20. Nas F, Ali M and Yahaya A (2017) Identification of some Enteric Bacteria from Diarrhoeic Stool Samples of Patients Attending Murtala Muhammad Specialist Hospital Kano, Nigeria International Journal of Advanced Academic Research | Sciences, Technology \& Engineering 3(9).

21. Obi CL, Coker AO, Epoke J and Ndip RN (1997) Enteric bacterial pathogen in stools of resident of urban and rural region in Nigeria. J Diarrhoeal Dis Res15(4): 241-247.

22. Kim NO, Jung SM, Na HY, Chung GT, Yoo CK, et al. (2014) Enteric bacteria isolated from diarrhoeal patients in Korea in 2004. Osong Public Health Res Perspect 6(4): 233-240.

23. Lopez MD, Gonzales ES, Valdes DM, Fragoso AT and Albizu CJ (1996) Wales, 1992-2003. Food control 18: 766-772.

24. Mengesha RE, Kasa BG, Saravanan M, Berhe DF, Wasihun AG, et al. (2014) Aerobic bacterial isolates from post- surgical wound and their antimicrobial susceptibility pattern: a hospital based cross-sectional study. E3 journal of medical research 3(2): 18-23.

25 Rivera-Chávez F, Bäumler AJ (2015) The pyromaniac inside you: salmonella metabolism in the host gut. Annu Rev Microbiol 69: 31-48.

\begin{tabular}{l} 
Your next submission with Juniper Publishers \\
will reach you the below assets \\
- Quality Editorial service \\
- Swift Peer Review \\
- Reprints availability \\
- E-prints Service \\
- Manuscript Podcast for convenient understanding \\
- Global attainment for your research \\
- Manuscript accessibility in different formats \\
( Pdf, E-pub, Full Text, Audio) \\
- Unceasing customer service \\
Track the below URL for one-step submission \\
https://juniperpublishers.com/online-submission.php \\
\hline
\end{tabular}

